Corrigendum

\title{
Corrigendum to "Determination of Hardness and Fracture Toughness of Y-TZP Manufactured by Digital Light Processing through the Indentation Technique"
}

\author{
Ziyu Mei $\mathbb{D}$, Yuqing Lu $\left(\mathbb{D}\right.$, Yuxin Lou $\mathbb{D}$, Ping Yu $\mathbb{D}$, Manlin Sun $\mathbb{D}$, Xin Tan $\mathbb{D}^{\text {, }}$ \\ Junjing Zhang $\mathbb{D}$, Li Yue $\mathbb{D}$, and Haiyang Yu $\mathbb{D}$
}

State Key Laboratory of Oral Diseases, National Clinical Research Center for Oral Diseases, West China Hospital of Stomatology, Sichuan University, Chengdu 610041, China

Correspondence should be addressed to Haiyang Yu; yhyang6812@foxmail.com

Received 20 April 2021; Accepted 20 April 2021; Published 3 May 2021

Copyright $\odot 2021$ Ziyu Mei et al. This is an open access article distributed under the Creative Commons Attribution License, which permits unrestricted use, distribution, and reproduction in any medium, provided the original work is properly cited.

In the article titled "Determination of Hardness and Fracture Toughness of Y-TZP Manufactured by Digital Light Processing through the Indentation Technique" [1], incorrect images were used for Figures 1 and 2 due to an error during the preparation of the manuscript. Figures 1 and 2 should be corrected as follows: 


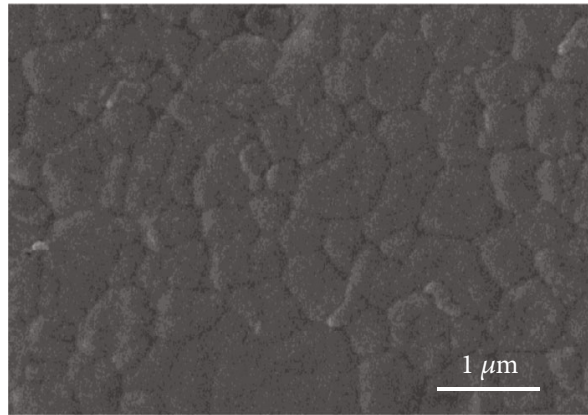

(a)

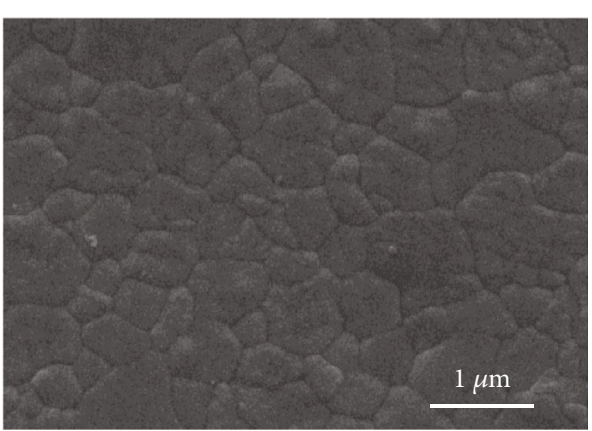

(b)

FIGURE 1: SEM images of the zirconia surface of the (a) DLP group and (b) MILL group at magnification $\times 40 \mathrm{k}$ and $\times 20 \mathrm{k}$.

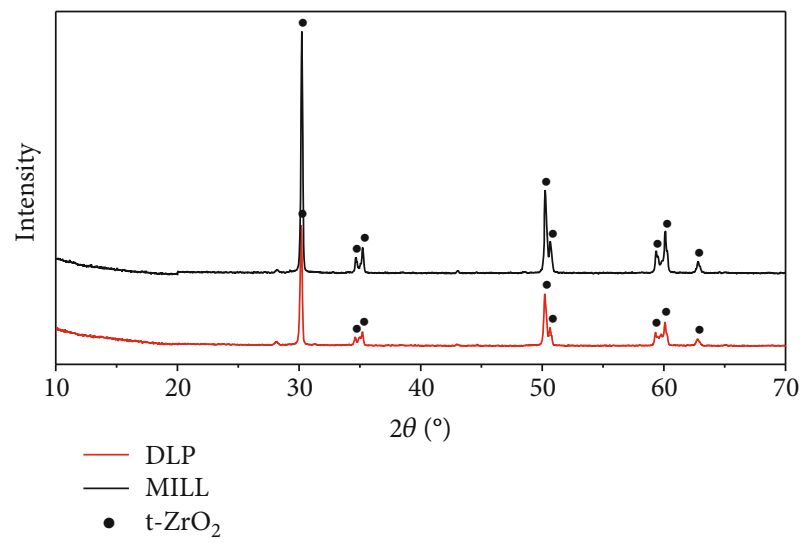

FIGURE 2: XRD patterns of zirconia.

\section{References}

[1] Z. Mei, Y. Lu, Y. Lou et al., "Determination of Hardness and Fracture Toughness of Y-TZP Manufactured by Digital Light Processing through the Indentation Technique," BioMed Research International, vol. 2021, Article ID 6612840, 11 pages, 2021. 